\title{
Transbordering assemblages: Power, agency and autonomy (re)producing health infrastructures in South East of England
}

\begin{abstract}
This paper discusses how intersecting identities, stigma, and health-based infrastructures are spatially affiliated and territorialised in the South East of England through the findings of three research projects aimed at understanding health inequalities among urban Black, Asian, and Ethnic Minorities including Gypsies and Travellers (BAME and GT) groups. It problematises Wacquant's approach to territorial stigma by explaining how Butler's notion of vulnerability and Castoriadis' notion of autonomous agency help to expand our understanding of the interplay between stigma and health infrastructures. Moreover, it suggests that such interplay requires an intersectional approach to identity as performative and embodied practice using illustrative examples. We propose that these health settings and infrastructures can be characterised as 'transbordering assemblages', following Irazábal (2014) who describes its embedded notions of pluri-locality (here and there: '[T]here'), pluri-identity and practices of bordering (being in or out/in and out/in between) when experiencing health needs.
\end{abstract}

\section{Keywords}

Health Infrastructures, Agency, 'Transbordering Assemblages', Learning Alliance, Autonomy, NHS, Covid-19.

\section{Introduction}

This paper discusses how intersecting identities, stigmas and health-based infrastructures are spatially affiliated and territorialised in the South East of England through findings of three research projects aimed at understanding health inequalities among urban Black, Asian and Minority Ethnic (BAME), including Gypsies and Travellers (GT). The literature on health and stigma (Bush et al., 2001; 
Cattell, 2001; Howarth, 2002; Airey, 2003; Popay et al., 2003; Kelaher et al., 2010; Keene and Padilla, 2010, 2014; Pearce, 2012; Wutich et al., 2014; Thomas, 2016; Garthwaite and Bambra, 2018) has illustrated the existing co-relationship between these two factors, which increases health inequalities among different social groups, such as ethnic minorities and low-income populations. This is the case in England, as shown by Garthwaite and Bambra (2018) and Thomas (2016), who rely on Wacquant's $(2007,2008,2009,2010)$ concept of territorial stigmatisation to illustrate such reality. For Wacquant, 'discourses of vilification' contribute to the creation of 'territorial stigmatisation processes' that prevent social groups from exercising their rights in the city. Wacquant shows how these place-based processes 'disqualify' social groups, depriving them of urban services and resources. For him, this 'territorial infamy' is at the core of identity formation and power relations, setting 'socially noxious consequences' (Wacquant in Thomas, 2016:2). In this paper, stigma is seen as a negative consequence of collective representations fastened in place.

Distancing ourselves from this perspective in which stigma is just spatialised in the urban territory, we argue that urban health infrastructures are crucial sites in which stigma is produced, reproduced, negotiated and renegotiated on a daily basis. We examine how processes of identity and stigma renegotiation are closely related to urban health infrastructures in some parts of the South East of England. Stigma is seen as a catalyst of new forms of identity in which social groups contest and try to overcome stigmatisation through their engagement with urban infrastructures. In other words, we argue that health-based infrastructures, in particular, can be understood as territorial sites of identity renegotiation in which stigma, vulnerability and agency, rather than being determined, are enacted and re-enacted in conflictual 
and tense ways when health service users, providers and other health stakeholders interact in daily life. Similarly, following Irazábal (2014), we propose that health infrastructures and the suburban corridor in the South East of England - as the sociogeographical context of our analysis - can be characterised as 'transbordering assemblages' embedded in notions of pluri-locality (here and there: '[T]here'), pluriidentity and practices of bordering (being in or out/in and out/in between). For example, contesting identity mechanisms are performed by self-perceived discriminated groups, enabling new forms of self-representation that grant them access to health services as illustrated below in the case of GT.

The methodological approach in this paper derives from qualitative data mostly gathered through three research projects carried out by a network of stakeholders comprising social scientist researchers, health service providers, charities, local government bodies and BAME representatives using the Learning Alliance approach as a re-adaptation of health services provision (Moreno-Leguizamon et al., 2015; Moreno-Leguizamon, 2017). The projects were focused on BAME and GT groups. The three projects were orientated to i) identifying the general health needs of BAME groups in Swale (Moreno-Leguizamon et al., 2015); ii) identifying issues of chronic pain among BAME people in Kent (Moreno-Leguizamon, 2016); and iii) exploring primary needs in terms of palliative and end-of-life care services among BAME and GT$^{1}$ groups in Dartford, Gravesend, Rochester, Chatham, Gillingham and Swale (Moreno-Leguizamon et al., 2017; Smith and Moreno-Leguizamon, 2017, Smith and Moreno-Leguizamon, 2019). These towns border Greater London and spread from the coastal crossings to the continent configuring a suburban corridor. Further, the qualitative research techniques used were varied. First, three pilot studies were

\footnotetext{
${ }^{1}$ These are the terms used in the English legal framework to define minorities in public policies.
} 
implemented, one in each project. Second, semi-structured interviews were conducted with selected informants within an intersectional lens, paying special attention to women from BAME and GT groups, as well as other stakeholders according to the research topic. On the whole, in the three research projects, 12 semi-structured interviews lasting between 40 and 60 minutes were conducted with Chinese, Eastern European, South American and Afro-Caribbean individuals, among others, either from the community or among health professionals. Third, eight focus groups were conducted with South Asian, Chinese and Afro-Caribbean females and males from the community and one with an inter-disciplinarian team of a pain community clinic. They lasted between 60 and 90 minutes. Fourth, two BAME meetings were organised in one of the three projects to provide health information and preliminary findings to these communities. They lasted at least two hours, including serving ethnic foods at the end of the events. Fifth, in one of the projects, local organisations were surveyed electronically to gain insights into the services they provide to BAME communities and how they monitor this delivery. The different research projects obtained ethical approval from the Ethical Board of the University of Greenwich and the National Health Service.

\section{Context(s)}

The proximity of this corridor to London makes these towns pluri-locale 'sleeping towns' or 'commuter towns' for active working populations who work in London and sleep and/or live [T]here in Kent. The 2011 census reported that 'those living in Kent and Medway and working in London are 107,427' (Office for National Statistics, Census 2011). Similarly, its public transport facilities include new fast trains that 
make the journey between Greater London and these towns last only a few minutes, and the journey between London and the coast takes approximately 70-90 minutes. During the past decade, due to an increase in housing prices in central London, this corridor has become a 'transbordering assemblage' (Irazábal, 2014), a site of absorption for a population displaced by financial speculation in the housing market (Smith and Moreno-Leguizamon, 2017). These people include young families of all ethnicities but particularly BAME families in search of larger spaces for children's recreation and a garden. Dartford, Gravesend, Rochester, Chatham, Gillingham (the last three are called Medway towns), Sittingbourne and Folkstone are all towns in the county of Kent in the South East of England (see Figure 1), which have small $(100,000)$ to medium-sized $(140,000)$ inhabitants.

\section{INSERT Figure 1 HERE}

According to the Kent County Council's (2019) summary of facts and figures, the population of Kent is nearly $1,568,600$, making it the largest among all counties in England. Of this total population, the white ethnic group represents $93.7 \%$ of all residents, while $6.6 \%$ are of the BAME origin. According to the same source, the largest single BAME group in Kent is Indian, which represents $1.2 \%$ of the total population. As mentioned above, the classification of minorities in England and Wales gives priority to the definition of ethnicity over citizenship in public policies.

The minority ethnic demographics in this suburban corridor show concentrations of the first-, second- and third-generation of migrant enclaves that have settled in Kent since the early twentieth century (the 1930s and 1940s). These communities are mainly represented by South Asians (Pakistanis, Bangladeshis and Indians), Black Africans and Black Caribbeans, among others. Kent has witnessed significant growth 
in its BAME ethnic profile, compared to the 2001 census in which it was reported as the smallest group (Jivraj, 2012). Kent's BAME population grew by $103 \%$ between 2001 and 2011, with the highest populations residing in North East Kent in Dartford, Gravesham and Medway, rendering it an accurate 'transbordering assemblage' of pluri-identity. Kent is also home to the country's largest GT population, estimated at 12,000 (The Traveller Movement, 2019). According to Smith $(2014,2017)$, this number is likely to be an underestimate as it only accounts for those who have selfidentified and/or are known to reside in caravans or on roadside sites, thus ignoring the majority of the population who are now in conventional housing; it also disregards the county's significant population of Roma migrants from East and Central Europe. In the UK, $40 \%$ of ethnic minority households have low incomes, which are twice the rate of white British households. Significant differences exist between groups, with Bangladeshis (70\%) and Pakistanis (60\%) classified as low-income households compared to Indians (30\%) and Black Caribbeans (20\%) (Trust for London, 2019). In general, ethnic minorities in both this area and across the UK are more likely to live in deprived areas, which impacts on their access to quality healthcare services. Covid-19 has brought this issue to light more prominently by making BAME groups doubly unlucky (The Economist, 2020).

Regarding other identity markers, such as religion and disability, the largest religious affiliation comprises Christians and Muslims, followed by Sikhs, Hindus, Buddhists and Jews. Following the national pattern, about $25 \%$ of individuals are reluctant to associate themselves with any religious affiliation (Kent Council County, 2019). In terms of disability, $17.6 \%$ of Kent's residents have an illness or condition that somewhat limits their daily routine activities (Kent Council County, 2019). As for other markers such as sexual orientation, it must be noted that the census of 2011 did not 
consider this as a category, excusing health institutions not to feel compelled to know about the quality of services provided to such individuals.

In the UK, the National Health Service (NHS) has the mandate to guarantee nondiscriminatory processes in both its employment and provision of health services. Since its inception in 1948, the NHS has been one of the leading socio-economic health infrastructures for the provision of free services at the point of delivery. Nonetheless, due to the effects of the financial crisis that started in 2008 , the NHS is currently facing intense competition from private and charity bodies. MorenoLeguizamon et al. (2015) suggest that to understand the British society, it is important to understand the role of the NHS as a symbol that embodies many ideological battles over the future of the state as either of welfare or neo-liberal nature. This understanding can be acquired through the philosophies of the three political parties, namely labour, conservative and the liberal-democrats; it can also be acquired from the current debate, including the Brexit ${ }^{2}$ debate, over whether Britain should be a society oriented more towards a closed monoculturism rather than an open multiculturalism. Similarly, as an institution, the NHS encapsulates much of the history and politics of Britain as it emerged from the colonial period. Unsurprisingly, Covid-19 has once again turned the spotlight on the NHS' discrimination against both BAME communities and other minorities and BAME health and social care professionals and as evident too in our three research projects of the past decade. The lack of attention of the political parties, the civil society and ethnic privileged groups in appreciating in the NHS a 'transbordering assemblage' (Irazábal, 2014) with the corresponding pluri-identity and pluri-locality are currently at the centre of

\footnotetext{
2 Brexit refers to the 2016 UK referendum on EU membership (Brexit vote) campaign resulting in its separation the EU. Some authors have observed how it came along with anti-diversity and racist feelings favouring a white nationalist perspective (See Burrell and Hopkins, 2019)
} 
debate in England where another government inquiry is trying to illuminate once more discrimination against BAME groups by the high number of deaths from Covid19.

From an anthropological perspective on urban or suburban infrastructures, the NHS cannot only be addressed through their technical function of being a health service provider but through its socio-historical and symbolic dimensions. Like any urban infrastructure, the NHS is a network, or better a transbordering 'assemblage' (Irazábal, 2014), that facilitates the flow of goods, services, people or ideas over the urban space (Larkin, 2016). In Collier's (2011) and Monstadt's (2019) views, such an infrastructure is also seen as an 'assemblage' of values, well-being policies, social practices, and institutional and administrative arrangements, which enables and at the same time constrains the urban health service provision. Furthermore, it is a 'transbordering assemblage' (Irazábal, 2014) where notions of identities, citizenship and belonging are reified and negotiated (von Schnitzler, 2016; Anand, 2011) in a context of dependency and vulnerability, as illustrated in our research. In a call for a conference on "urban vulnerabilities: infrastructure, health, and stigma", held on 8 June 8 2018, Yacobi and Baumann highlighted this aspect by quoting Gandy (2005), who refers to infrastructures as an 'exoskeleton' - extensions of our bodily selves on which our survival depends. This ontological 'dependency on infrastructure' (Butler, 2016) makes human bodies, as well as urban systems, vulnerable and, thus, turns infrastructures into particularly salient sites for interrogating urban stigmas from an embodied point of view.

In the UK, the NHS and other public bodies are governed by the Equality Act of 2010, which considers various forms of exclusion and discrimination, leaving behind the information silos approach of previous years that compartmentalised people's 
experiences into one legal category, failing to reflect the 'transbordering assemblage' (Irazábal, 2014) complexity of social identifications (Krizsan et al., 2012). Further, in as much as it is a legislative and policy act, the Equality Act of 2010 is one of the first frameworks that reassembles the principles of intersectionality, given that it does not identify a unique and singular category (e.g. ethnicity or gender) as the only driver of discrimination or inequality (Crenshaw, 1989). A review of all the current equality regimes in Europe (Krizsan et al., 2012) suggests that, in general, intersectionality as a framework in Europe is still in the process of being institutionalised, with the UK being among the leaders in Europe, along with Germany and France.

The Equality Act makes government bodies and, in particular, health providers responsible for assessing and monitoring all identity strands in health issues, considering race, ethnicity, gender, disability, sexuality, income and age. However, despite efforts to include diverse social groups at policy and provision levels, other actors such as charities in the UK (non-governmental organisations outside UK), academia and community-based organisations have pointed out the persistent obliteration of a serious intersectional perspective in the health sector and others (Moreno-Leguizamon et al., 2015; Moreno-Leguizamon et al., 2017).

As a possible theoretical context to working on issues of urban identity, intersectionality focuses on examining the overlapping of life experiences with identity markers, power, privilege and oppression (Hankivsky and De Leeuw, 2011). It focuses on capturing the dynamic relationship of the simultaneity and mutuality of identity markers to avoid 'essential' categories to provide a more comprehensive account on how fluid identity and difference are produced and reproduced in the context of power relations. It challenges the homogenisation of any group by including differences within differences for which power can be the driver of 
resistance and agency at the same time (Bastia, 2014). We consider intersectionality to be a vital framework and context for understanding the fluidity of the 'transbordering assemblages' (Irazábal, 2014) of identities, stigmas and vulnerabilities around health infrastructures.

\section{Health geopolitics: subjectivities and the (re)creation of territorialities and stigmatisation}

At first sight, it could be said that the health geopolitics in London's suburbs, Kent and the UK are formally built on a set of institutions (mainly but not only the NHS) grounded on a physical territory with apparent managerial functions with fixed borders as in the case of the local NHS Trusts, for example. However, anthropology has challenged this functional understanding of institutions and their territoriality and, consequently, socio-economic infrastructures when observing their discontinuous, albeit interconnected, and hierarchical relations on different international, national, regional and local scales (Gupta and Ferguson, 1992). This anthropological view, in which spaces are co-created, related, performed and constituted by social diversity, power and privilege, is used in this paper to further the discussion of intersecting identities, health infrastructures and stigmatisation. In other words, health infrastructures and stigma in this part of the South East of England can be seen as co-created upon intersectional identities that are fluid, hybrid and dynamic (e.g. the way BAME and GT groups interact with health service providers).

This is illustrated by our qualitative research findings obtained mainly through focus groups, interviews and observations. These results can be synthesised into three broad themes in an attempt to understand the specific health concerns of BAME and 
GT groups in this part of the South East of England, which include i) a lack of trust between various minority groups through various markers (gender, race, ethnicity, age, religion, accent, time in the UK) and the health services arising from mutual relational stigma and prejudice; ii) a lack of knowledge and awareness of health services and other socio-economic infrastructures by different minorities; and iii) health professionals' and other health authorities' lack of familiarity with cultural nuances, existing stigmas and ambiguities of minorities when accessing health services (Moreno-Leguizamon et al., 2017). The following examples illustrate these points.

\section{Example 1:}

Because of stigmatisation, some GT individuals in one of the research projects shared how they use fluid forms of self-identification according to the circumstances when approaching health services. If possible, they would disguise or pass themselves as 'white British' to avoid their historical self-perceived discrimination and stigmatisation at the hands of the health services, which is a recurrent feeling for them and a frequent research theme when inquiring about health services with this group. In this example, ethnicity, race and locality intersections work as devices allowing GT to play as a passing strategy that enables them to access health services and interact with health infrastructures. At this point, the question of 'authenticity' becomes secondary, while the resistance mechanism becomes primary. Not being less legitimate for this reason, GT's identity negotiation strategy grants them the needed services by creating ethnic sameness within difference. It is their sense of agency and self-representation that catalyses such resistance to historically undermining forms of ethnic and racial representations of GT. This negotiation strategy involving resistance and agency over their ethnic identity was commonly 
identified in the interviews in one of the research projects in relation to palliative and end-of-life care services within this community. As noted above, the official census of GT groups embodies this ambiguity, which makes it difficult to determine their numbers in Kent County and nationally. GT groups were counted for the first time in the 2011 census, and its low number $(58,000)$ in England and Wales forced the government to acknowledge some undercount, which eventually illustrated selfrepresentation and self-identification as non-GT individuals before institutions (UK Parliament, 2019).

\section{Example 2:}

During a focus group, some women carers of Afro-Caribbean ethnic origin said that they did not wish to be in any care facility for older people in England when they are older. Because of their experiences of racism and stigmatisation as carers when working in nursing homes, hospitals, hospices and other health facilities, they did not want to imagine how the situation would be if they were patients there. This research finding was interesting in terms of their time in the country. Because of their accent and ethnicity, some health workers (carers) who had arrived in the UK recently felt more vulnerable than those who came from the same ethnic group but were born in the UK and had a 'British' accent. Paradoxically, England, before and after Brexit, desperately needs carers due to an increase in older populations, including the BAME populations. The workforce base in health and social services in the UK consists of women who, in most part, come from ethnic minorities. Women and ethnic minorities (e.g. Filipinos, Nigerians and Indians) are involved in the health care economy of the UK. According to Morris (2019), 'of the 1,216,719 staff members working in the NHS in September 2018, 935,772 were women $(77 \%$ of the 
workforce)'. Moreover, regarding ethnicity, the House of Commons (2019) reports thus:

[Nearly] $7.1 \%(21,930)$ of nurses report an Asian nationality. Of these, $92 \%$ are either Filipino or Indian; $6.4 \%(19,849)$ of nurses report an EU nationality other than British. Of these, 53\% are either Irish, Spanish or Portuguese. There are 7,256 nurses with an African nationality (2.3\%). The highest 'Other' nationality is Jamaican, with 466.

This example illustrates how intersections of gender, ethnicity, location, race, migratory status and age are at stake for a main group of carers in the UK. A visible tension described by these women indicates that while their job and role within the health infrastructure position them differently in their professional field to meet their economic needs, they also represent an undesirable situation that perpetuates traditional gender roles, as well as ethnic and racial stigmas. Interestingly, while migrating from their home countries might have created new opportunities to empower them economically, at the same time, it has confronted them with production and reproduction processes of racial stigmatisation.

\section{Example 3:}

There seem to be 'transnational healing routes' that contain predominantly Christian West African males, with mental health issues. These patients swing between the health services in the UK and traditional healers in West Africa in search of effective treatments. In other words, seeking to be cured, these patients appeal to healers and other medicinal practices in their home country to be treated for their maladies. These practices involve face-to-face consultations with healers in West Africa in countries such as Sierra Leone. At the same time, they are a cause for concern for families, 
carers and local health authorities (e.g. general practitioners [GPs]) due to the instability this pattern creates between being here and there (Jusu, forthcoming). These transnational healing routes create complex issues of identity, vulnerability and stigma at home - wherever home is - and abroad. Thus, this case shows international back-and-forth movements between medical systems and infrastructures, illustrating the intersection of pluri-locality with mental health stigma here and there ' $[T]$ here', The lack of understanding and knowledge about these African patients in London forces them to seek a possible cure in their places of origin. That most cases are males is significant in this case and possibly connected to a generation that fled wars.

\section{Example 4:}

According to the literature (Metro, 2008, 2018), lesbian, gay, bisexual, transgender, questioning and/or queer (LGTBQ) individuals are marginalised according to their ethnicity, race, age and/or religion. In comparison to other groups, they experience challenges within both their own and other communities, depending on stigmatising attitudes towards them. Health problems experienced by these groups are closely related to identity when requiring health services in some cases. For example, older gay couples requiring palliative and end-of-life care services may not be identified as a 'married couple' due to the novelty of the marriage institution in this community, which presents health professionals with difficulties when they intend to provide information to the 'partner' or family in the traditional sense of the word. It seems that for young gay couples, this is not an issue as such. However, the intersectionality of gender, sexual orientation, education, social class and location (inside or outside London) make each case more complicated and in need of more research. Nonetheless, these factors are rarely considered by health practitioners who 
increasingly need to understand and put into contexts the health needs of these different groups to satisfy them effectively.

\section{Example 5:}

In one of the interviews on chronic pain among BAME individuals, a female informant expressed herself through her husband. Given her lack of fluency in English, this woman chose not to reveal her bodily symptoms with her voice and words. It was her husband who characterised her pain and health conditions using his own filtered account about his wife's body and expressions. He also described his help with the daily chores at home, such as cooking, as well as washing the dishes and clothes, while his wife was ill. The situation of carers or loved ones translating/mediating for patients who do not speak the local language is common in many health services. In some places active in decreasing gender violence, medical protocols recommend that women should have a private and confidential interaction with health providers, such as physicians or nurses. Considering that women are the most common victims of violence in domestic and private spaces, health providers need to include medical protocols that assure women of confidentiality. Thus, the intersection between gender, pain and 'a lack of voice' in all its meanings when one is not a native speaker of a language is one that requires further research. The accent is another intersectional marker that generates a very 'subtle' discrimination, within the NHS, for example, being an infrastructure in which the hierarchy of clinical and managerial roles (bands) relates to so-called "posh" British accent and other accents.

The brief examples above illustrate how health infrastructures exceed physicalgeographical dimensions to become discontinuous and interstitial sites in which intersecting subjectivities, stigmas and identities (ethnicity, race, gender, age, sexual 
orientation, accent, migration status and place of birth) are negotiated and positioned differently depending on the local daily health infrastructure encountered. Similarly, these examples illustrate that these groups are inscribed in territorial affiliations and health use/provision of services that can be better defined as territorialities in as much as identity, power, stigma and citizenship are in most cases at stake. This is either through first-generation migrant access to services or by the provision of NHS services by nurses and doctors recruited from all over the world, especially Africa or South Asia. In the case of women, especially women who belong to ethnic, racial or religious minorities, it is clear that such identity markers position them in less empowered conditions to enable them to negotiate or mediate in their interest.

As stated above, health settings and infrastructures characterised as 'transbordering assemblages' (Irazábal, 2014) enable urban experts, planners, managers and practitioners to analyse notions of boundaries, restrictions, stigmas, margins and regulations that permit or limit subjects to be in or out of such infrastructures or assemblages. We are convinced that these fluid processes enable subjects to adapt and negotiate within the health infrastructure by assuming different positions that transcend sites and limits such as those relating to people when they face stigmatisation because of who they are (ethnicity, race, gender, age, physical abilities [ableism], sexual orientation, locality, language or religion) (Irazábal, 2014; Tovar-Restrepo, 2014).

As illustrated in the examples, various groups have developed strategies to not only contest and resist stigmatisation but also produce new forms of self-representation and intersectional difference or sameness, with subsequent subjective contents and life opportunities. As in the presented cases, health infrastructures in the South East of England allow the observation of flexible and transbordering mobility within the 
geopolitics of health in which agentic processes can sprout, and therefore, the emergence of new institutions and subjectivities can pave the way for more autonomous ways of being and living for the minorities and the majorities.

In sum, like Irazábal (2014), we can say that health infrastructures deal with degrees of liminality, hybridisation and syncretism, which include and also surpass issues of identity and stigmatisation in multiscalar ways: local, regional, international and global. We also consider that these negotiation processes and different interactions shall be looked at theoretically through a lens of vulnerability and infrastructure, as seen by Butler (2016), and also agency and subjective autonomy, as suggested by Castoriadis (1975).

\section{Are transbordering health infrastructures implicated in the production of stigma, resistance, agency and autonomy?}

The relationship between the stigma experienced by BAME groups including GT groups and their consequential vulnerability in health service provision is documented in the literature on health and stigma, as well as in our research findings. Butler $(2016: 16,24)$ refers to vulnerability as an existential condition or inner codependency of subjects. Her notion of vulnerability is given an ontological status, characterising it as the intrinsic intersubjective dimension of being. For this reason, it is crucial to address the existing relationship between vulnerability, stigma and the health infrastructures that are required to fulfil basic material and psychical conditions of living. This approach supports not only the subject's bodily biological dimensions but also the 'institutional structures and social worlds', which inform and give life to such bodies. Butler (2016:19) states the following: 
We cannot talk about a body without knowing what supports that body and what its relation to that support - or lack of it - might be. In this way, the body is less an entity than a relation, and it cannot be fully dissociated from the infrastructural and environmental conditions of its living.

Butler correctly calls for rethinking the relationship between the human body and health infrastructures knowing that neither the body nor the self is a discrete, singular or self-sufficient entity of its own social institution or society.

Embodiment for Butler is both performative and relational. Relationality includes a dependency on health infrastructural conditions and legacies of discourse, as well as institutional power that precedes and conditions subjects' existence. She adds the following:

By theorising the human body as a certain kind of dependency on infrastructure, understood complexly as environment, social relations and networks of support and sustenance by which the human itself proves not to be divided from the animal or from the technical world, we foreground the ways in which we are vulnerable to decimated or disappearing ... infrastructures, economic supports and predictable and well-compensated labour. Not only are we then vulnerable to one another - an invariable feature of social relations - but, in addition, this very vulnerability indicates a broader condition of dependency and interdependency. (Butler, 2016:21)

Social resistance is closely associated with health infrastructures and the same stigma and vulnerability experienced in satisfying or failing to satisfy subjects' health needs (Butler, 2016:19). Thus, like Butler, we can say that stigma and its 
consequential vulnerability are not the opposite of resistance; on the contrary, they can be seen as catalysts (Butler, 2016:21). She argues thus:

If we understand the way vulnerability enters into agency, then our understanding of both terms can change, and the binary opposition between them can become undone. I consider the undoing of this binary a feminist task ... vulnerability is not a subjective disposition. Rather, it characterises a relation to a field of objects, forces and passions that impinge on or affect us in some way. As a way of being related to what is not me and not fully masterable, vulnerability is a kind of relationship that belongs to that ambiguous region in which receptivity and responsiveness are not clearly separable from one another and not distinguished as separate moments in a sequence; indeed, where receptivity and responsiveness become the basis for mobilizing vulnerability rather than engaging in its destructive denial. (Butler, 2016:25)

As illustrated in our examples, subjects react to instituted stigmas, mechanisms or practices that exclude or prevent them from fully accessing health provision. In this study, women and minorities generate strategies to oppose, blend in, operate or negotiate in environments in which their intersecting identities are neither powerpositioned nor reflect the instituted norm of power(s). This is the productivity of the agentic power that Butler $(2016: 19)$ also sees operating in health infrastructures where 'queer' developments can happen. In effect, health infrastructures in the South East of England can be seen as productive sites, which give way to or open up new avenues to subjective content surpassing stigmas, norms, constraints and boundaries. These define social institutions or identities built on forms of inequality or submission. The relationship between infrastructures, stigma, vulnerability and 
agency that Butler presents is useful in explaining the above characteristics of health infrastructures in the South East of England as sites of negotiation, transbordering, resistance and productivity, as we have attempted to illustrate them in our examples. However, we disagree with Butler's post-structuralist view that the productivity of such processes is reduced, limited and entirely determined by power ${ }^{3}$. In our opinion, it is necessary to examine such processes from a different theoretical lens by considering crucial notions that are at stake, such as intersubjectivity and agency.

Castoriadis' (1975) notions of agency and autonomy allow us to understand these negotiation dynamics and the emergence of social institutions and forms of identity as new subjectivities and institutions that are not entirely determined by power. His notion of agency is understood as the relationship between the psychical and social poles of the subject through which the subject becomes aware of its own selfconstitution as a social institution. The individual can acknowledge her/himself as a social product or as a representation that can put itself into question and take deliberate actions against exclusions driven by social stigmas. In other words, the individual is a subject of action capable of questioning and changing the very world that has provided its own identity (Castoriadis, 1975:70; Tovar-Restrepo, 2012). Agency, alongside its creative capacity, allows both subjects and societies to transcend resistance and create new and autonomous forms, institutions, identities or ways of being. At this junction, neither social institutions nor subjects are reduced

\footnotetext{
${ }^{3}$ As an author whose performative theory of the self is inspired by Foucault's poststructuralist arguments, for Butler the notions of resistance and productivity do not allow philosophical or psychoanalytical allusions to autonomy. The poststructuralist notion of agency is exhausted in a resistance that is anchored in the deterministic and pervasive character of power that dominates any possible subjective change or historical rupture. Thus, as Foucault, Butler relates resistance to words and comparisons between "better or worse" forms of life, or even uses the word 'freedom' to describe social practices, understandings or political positions. However, the discussion about resistance and normative standards through which to distinguish among collective choices, social practices and forms of life is never exhausted or satisfactory, which risks a fall into a naïve relativism (Tovar-Restrepo, 2012).
} 
to a passive product of superior forces. The subject is not a mere bearer of society's contents in which the only possibility is to resist instituted power or stigmatisation.

Through the concept of autonomous agency, Castoriadis (1975) opens a path towards reclaiming our critical self-reflectiveness and our capacity as societies and subjects to give ourselves our own laws and institutions. Although these institutions cannot be exempt from the exercise of power, as shown in the case of intersectional identities relating to health infrastructures in the access and delivery of services, they are 'not just' another form of subjecting power.

This discussion becomes essential to our view on how health infrastructures shall be, or can be, catalysts of autonomous social institutions, subjectivities and agentic transformations as a social project. To accomplish such a goal, we believe that it is necessary to hold a theory of intersubjectivity that integrates different regions or dimensions of the self and its world: physical, natural and biological, psychical, and social. This would explain their mutual co-dependency without being determined by power and stigmatisation. Equipped with a non-determined and creative agency, Castoriadis' (1975) subject is able to judge and select from among social institutions and practices in which autonomy works as both a normative standard and a political option (also see Kalyvas, 1998; Tovar-Restrepo, 2012).

More concretely, through research about BAME, GT and LGTBQ communities in the South East of England, we have identified potential mechanisms that could foster more autonomous agentic transformations within health infrastructures. These mechanisms include infrastructures that are constitutively multicultural and prepared to include complexity and differences, combat implicit racial and cultural bias, and guarantee healthcare service provision to all. Healthcare in hospitals and GP 
protocols can be expanded so that initial interviews with patients can contain questions related to gender and sexual differences; care architecture and networks, locally and abroad; cultural background, daily practices and beliefs about their body, pain, health and cures; the role of alternative versus conventional medicine; how their health relates to other areas of their life and subjective dimensions (i.e. sexuality, income level); and how transnational movement or location in the city impacts on their access to health services. All these aspects shall be taken into account when formulating the aims and objectives in health program evaluations.

Another possible way to open a more productive dialogue with minorities and women is by inviting non-governmental organisations (NGOs/charities in the UK) or civil society groups that work closely with them, with agendas that aim to recognise their cultural and racial diversity, as well as their rights. As facilitators, NGOs (e.g. women's organisations) play an important role in sharing a more comprehensive understanding of minorities' experiences and challenges and offer them valuable information on employment opportunities, day-care facilities for children, language classes or information technology.

By fully understanding how aspects of gender, culture and intersectionality inform the health of minorities, healthcare services can be significantly improved in terms of their effectiveness, quality and equity. Undoubtedly, this approach to viewing and listening to settled minorities, women and new migrants will benefit vulnerable social groups and contribute to the attainment of greater equity in healthcare provision. This provision can be taken into account when providing primary, secondary and tertiary health services within the suburban corridor between London and Kent. GPs, hospitals and emergency rooms such as Medway Maritime, Darent Valley and University Lewisham Hospital. 


\section{Conclusion}

We examined the relationship between health infrastructures and stigma, illustrating how stigmatisation is produced and negotiated by women and cultural and racial minorities as in the case of BAME and GT groups. These groups also included other stakeholders, such as health professionals and practitioners, as permitted by the Learning Alliance through the three research projects. We contributed to the stigma debate by showing that stigma is not a fixed category but a dynamic one that includes the mechanisms of resistance, which can catalyse and produce new social identities and forms of subjectivity not entirely determined by power. Furthermore, by drawing on the transbordering assemblage concept to define urban and suburban health infrastructures within their own context, we offered a new understanding of health institutions (e.g. NHS) and service provisions (NHS primary and community care) where different stakeholders are active agents that can overcome social stigmas by integrating a diverse range of unheard voices.

In this paper, subjective content and identities were negotiated, done and undone within liminal and hybrid contexts in which health providers, patients, researchers and other diverse actors co-exist. This text shows how gender and cultural rights understood as the right not to be discriminated against because of gender and cultural differences - need to be incorporated into the practices of healthcare infrastructures (NHS in the case of the UK), along with social and civil rights, in conjunction with the pattern of broadening democratic rights. Examples presented in this paper of the experiences of GT groups, LGTBQ community members or BAME women show their agentic potential for overcoming and negotiating stigmatisation 
and claim for their rights within health social institutions. As a result, we agree with Lara (2002:218) that the recognition of gender and cultural rights increases service provision and widens democracy. Indeed 'democracy can only be expanded by opening it up culturally'.

Finally, by suggesting Castoriadis' (1975) work as a theoretical framework that can deepen our understanding of social aspects around health infrastructures, stigmatisation and agency, this research managed to make further contributions. As defined by Castoriadis, agency enables us to question and resignify social institutions (i.e. urban and suburban health infrastructures) that can become catalysts of autonomous identities, subjectivities and ways of being, transcending mere resistance with its creative power of radical imagination. Our examples illustrate potential and necessary actions to include different identities, subjectivities and forms of self-representation where power is not a determinant, and women, LGTBQ, BAME and GT groups can resignify health infrastructures, particularly during and after Covid-19. The challenge for health infrastructures, therefore, is to base their examinations and self-reflections on autonomy as both an aim and a process. Rather than only emphasising issues of stigma and resistance within infrastructures, more deliberate work can be carried out to seek autonomous subjects who are capable of building new health social institutions in which our own diverse subjectivity as a common and political project is at stake, as addressed by Castoriadis.

\section{References}

Airey L (2003) "Nae as nice a scheme as it used to be": lay accounts of 
neighbourhood incivilities and well-being. Health Place 9(2): 129-137.

Anand N (2011) PRESSURE: The PoliTechnics of water supply in Mumbai. Cultural Anthropology 26(4):542-64.

Bastia T (2014) Intersectionality, migration and development. Progress in Development Studies 14(3): 237-248.

Burrell K and P. Hopkins (2019) Introduction: Brexit, race and migration. Environment and Planning C: Politics and Space 37(1): 3-40.

Bush J, Moffatt S and Dunn C (2001) 'Even the birds round here cough': stigma, air pollution and health in Teesside. Health Place 7(1): 47-56.

Butler J (2016) Rethinking Vulnerability and Resistance. In: Bultler J, Gambetti Z and Sabsay L (eds) Vulnerability in Resistance. Durham: Duke University Press, pp.13-27.

Castoriadis C (1975) The Imaginary Institution of Society. Cambridge: MIT Press.

Cattell V (2001) Poor people, poor places, and poor health: the mediating role of social networks and social capital. Social Science \& Medicine 52(10): 15011506.

Collier SJ (2011) Post-Soviet Social: Neoliberalism, Social Modernity, Biopolitics. Princeton, NJ: Princeton University Press.

Crenshaw K (1989) Demarginalizing the intersection of race and sex: A black feminist critique of antidiscrimination doctrine, feminist theory and antiracist politics. University of Chicago Legal Forum, Article 8: 139-167.

Gandy M (2005) Cyborg urbanization: complexity and monstrosity in the contemporary city. International Journal of Urban and Regional Research 29(1): 26-49. 
Garthwaite K and C. Bambra (2018) 'It's like being in Tattooville': An ethnographic study of territorial stigma and health in a post-industrial town in the North East of England. Health and Place 54:229-235.

Gupta A and Ferguson J (1992) Beyond Culture: Space, Identity and Politics of difference. Cultural Anthropology 7(1):6-23.

Hankivsky O (2011) Introduction. In: Hankivsky O (ed) Health Inequities in Canada: Intersectional Frameworks and Practices. Vancouver-Toronto: UBC Press.

House of Commons (2019) NHS staff from overseas: statistics. Briefing Paper no. 7783, UK, 4 June. $\quad$ Retrieved from https://commonslibrary.parliament.uk/research-briefings/cbp-7783/.

Howarth C (2002) 'So, you're from Brixton?' The struggle for recognition and esteem in a stigmatized community. Ethnicities 2(2): 237-260.

Irazábal C (2014) Introduction. In: Transnationalism and indigenous citizenship in Latin America. In Irazábal C (ed.) Transbordering Latin Americas: Liminal places, cultures, and powers (t)here. New York, NY: Routledge, pp.1-22.

Jivraj S (2012) How has ethnic diversity grown 1991-2001-2011? Report, University of Manchester, Joseph Rowntree Foundation, UK, December.

Jusu, S (forthcoming) How the Explanatory Models and Health Seeking Behaviours among service users and their carers from Sierra Leone contribute to their Pathways to Care. PhD thesis, University of Greenwich, UK.

Kalyvas A (1998) Norm and Critique in Castoriadis' theory of autonomy. Constellations 5(2): 161-168.

Kent Council County (2019) Summary of facts and figures. Available at: https://www.kent.gov.uk/about-the-council/information-and-data/Factsand- 
figures-about-Kent/summary-of-kent-facts-and-figures\#tab-2 (accessed 8 September 2019).

Krizsan A (2012) Institutionalizing intersectionality: a theoretical framework. In: Krizsan A, Skjeie, H and Squires J (eds) Institutionalizing Intersectionality The Changing Nature of European Equality Regimes. London: Palgrave McMillan, pp.1-32.

Keene D and Padilla M (2010) Race, class, and the stigma of place: moving to 'opportunity' in Eastern lowa. Health Place 16(6): 1216-1223.

Kelaher M, Warr D, Feldman P and Tacticos T (2010) Living in Birdsville: exploring the impact of neighbourhood stigma on health. Health Place 16(2): 381-388.

LAPCEL: The Leaning Alliance for Palliative and End of Life Care. Available at: https://www.youtube.com/watch?v=TJnujJ1JFEM (accessed 8 September 2019).

Lara P (2002) Democracy and Cultural Rights: Is There a New Stage of Citizenship? Constellations 9 (2): 207-220.

Larkin B (2013) The Politics and Poetics of Infrastructure. Annual Review of Anthropology 42: 327-343.

The Metro Centre (2008) We are bovver'd: Responding to the needs of lesbian, gay, bisexual and transgender young people in South and East London. Available at:

https://www.metrocentreonline.org/sites/default/files/201704/We\%20are\%20 Bov verd\%202008.pdf (accessed 7 December 2019).

The Metro Centre (2016) Youth Chances: Integrated Report. Available at: https://www.metrocentreonline.org/sites/default/files/201704/National\%20 
Youth\%20Chances\%20Intergrated\%20Report\%202016.pdf (accessed December 2019).

Monstadt J (2019) Cities in an era of interfacing infrastructures: Politics and spatialities of the urban nexus. Urban Studies 56(11): 2191-2206.

Moreno-Leguizamon C, Tovar-Restrepo M, Irazábal C and Locke C (2015) Learning alliance methodology: Contributions and challenges for multicultural planning in health service provision: A case study in Kent, UK. Planning Theory \& Practice 16(1): 79-96.

Moreno-Leguizamon C (2016) Social Sciences and Humanities Contribution to Pain Research: Notes from Ethnographic and Auto-ethnographic Accounts of Black and Ethnic Minority People (BME) in Chronic Pain. Available at: https://www.ucl.ac.uk/encounteringpain/programme/accepted-abstracts (accessed 7 December 2019).

Moreno-Leguizamon C, Smith D, Spigner C (2017) Positive aging, positive dying: intersectional and daily communicational issues surrounding palliative and end of life care services in minority groups. In: Docking $\mathrm{R}$ and Stock $\mathrm{J}$ (eds) International Handbook of Positive Aging. London: Routledge, pp.21-37.

Morris E (2019) The role of women in the NHS in England. In: Pharmafield.

Available at: https://pharmafield.co.uk/healthcare/the-role-of-women-in-thenhs-inengland/ (accessed 7 December 2019).

Office for National Statistics (2001) Census 2011 Location of usual residence and place of work by method of travel to work. Available at: https://www.statistics.digitalresources.jisc.ac.uk/dataset/wu03uk-2011smsmerged-lala-location-usual-residence-and-place-work-methodtravel-work 
(accessed 7 December 2019).

Pearce J (2012) The 'blemish of place': stigma, geography and health inequalities. A commentary on Tabuchi, Fukuhara \& Iso. Social Science \& Medicine 75(11): 1921-1924.

Popay J, Thomas C, Williams G, Bennett S, Gatrell A and Bostock L (2003) A proper place to live: health inequalities, agency and the normative dimensions of space. Social Science \& Medicine 57 (1): 55-69.

Smith D and Moreno-Leguizamon C (2017) Learning alliance approaches to working with BME communities on healthcare innovation: a case study in palliative and end-of-life care services. In: Craig G (ed) Community Organising Against Racism, 'Race', Ethnicity and Community Development. London: Policy Press, pp.81-96. https://doi.org/10.2307/j.ctt22p7kd6.12.

Smith D, Moreno Leguizamon C (2019). Engaging Black and Minority Ethnic (BME) elders in palliative care innovation through the Learning Alliance in Palliative and End of Life Care (LAPCEL) methodology. Palliative Medicine \& Care International Journal 1(3): 555564. 10.19080/PMCIJ.2019.01.555564.

The Economist (2020) Doubly unlucky: British Pakistanis and Bangladeshis have been hit hard by covid-19, 6 June, 19. Available at: https://www.economist.com/britain/2020/06/06/british-pakistanis-andbangladeshis-have-been-hit-hard-by-covid-19.

The Traveller Movement (2019) Available at: https://www.travellermovement.org.uk/about (accessed 8 September 2019)

Thomas G (2016) 'It's not that bad': Stigma, health, and place in a post-industrial community. Health Place 38: 1-7. 
Tovar-Restrepo M (2012) Castoriadis, Foucault, and Autonomy: New Approaches to Subjectivity, Society, and Social Change. London: Continuum Books.

Tovar-Restrepo, M (2014) Nations within nations: Transnationalism and indigenous citizenship in Latin America. In Irazábal C (ed.) Transbordering Latin Americas: Liminal Places, Cultures, and Powers (t)here. New York, NY: Routledge, pp.149-165.

Trust for London Available at: https://www.trustforlondon.org.uk/ (accessed 8 September 2019).

United Kingdom Parliament (2019) What we know about inequalities facing Gypsy, Roma and Traveller communities. Available at: https://publications.parliament.uk/pa/cm201719/cmselect/cmwomeq/360/ report-files/36005.htm (accessed 6 December 2019)

Von Schnitzler A (2008) Citizenship prepaid: water, calculability, and technopolitics in South Africa. Journal of Southern African Studies 34(4): 899-917.

Yacobi H and Baumann H (2018) Call for Papers: Urban vulnerabilities: infrastructure, health, and stigma workshop, University College London, 8 June. Available at https://www.ucl.ac.uk/bartlett/development/events/2018/jun/urbanvulnerabilities-infrastructure-health-and-stigma.

Wacquant L (2007) Territorial stigmatization in the age of advanced marginality. Thesis Eleven 91(1): 66-77.

Wacquant L (2008) Urban outcasts: A comparative sociology of advanced marginality. Cambridge: Polity Press.

Wacquant L (2009) Prisons of Poverty. Minneapolis: University of Minnesota Press. 
Wacquant L (2010) Crafting the neoliberal state: workfare, prison fare, and social insecurity. Sociological Forum 25(2): 197-220.

Wutich A, Ruth A, Brewis A and Boone C (2014) Stigmatized neighborhoods, social bonding, and health. Medical Anthropology Quarterly 28(4): 556577. 


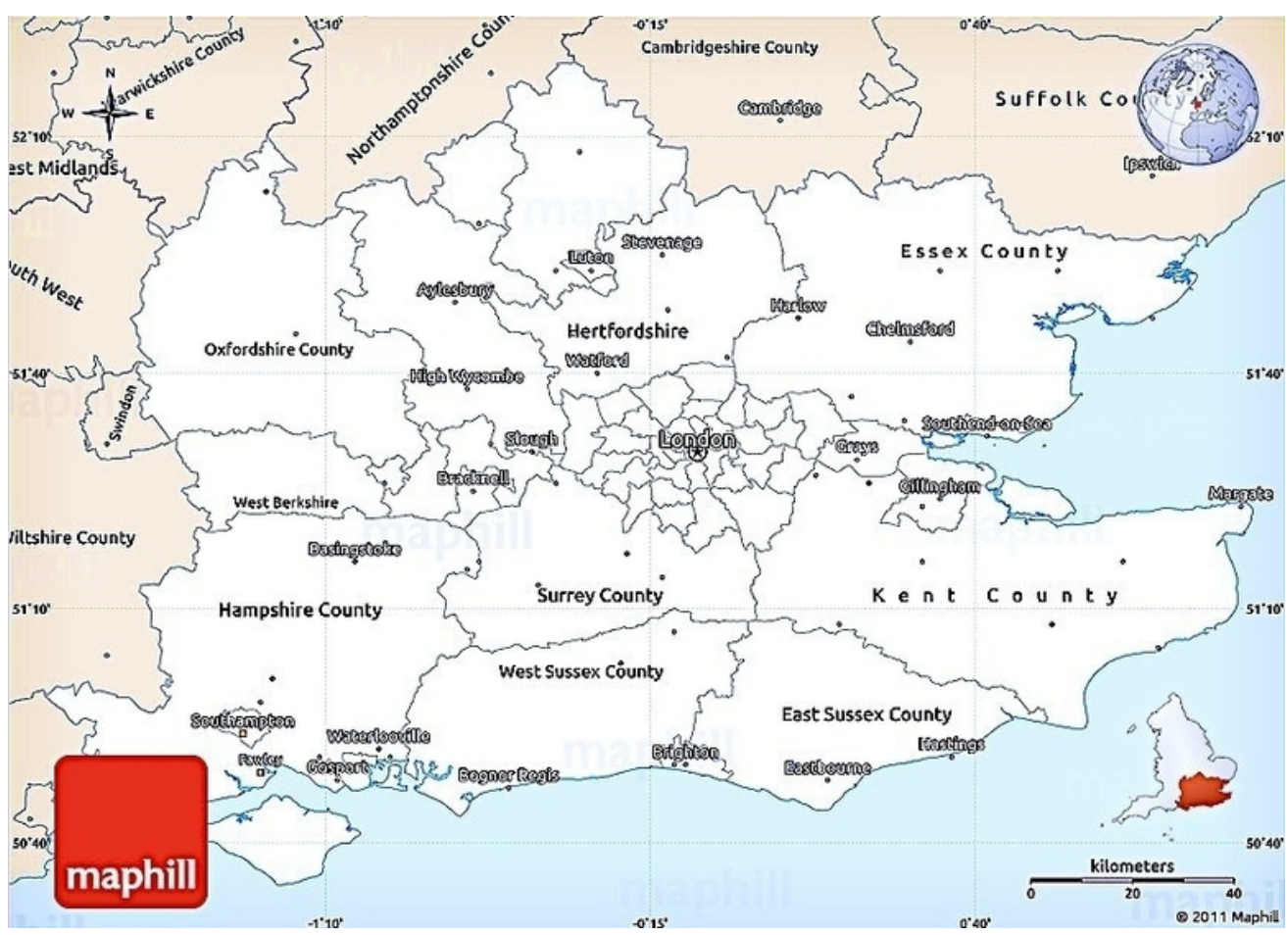

Figure 1. Map: South East of England (c) Maphill/CC BY-ND

$131 \times 93 \mathrm{~mm}(150 \times 150 \mathrm{DPI})$ 